\title{
Social inequalities in breast cancer mortality among French women: disappearing educational disparities from 1968 to 1996
}

\author{
G Menvielle $^{*, 1,2}$, A Leclerc ${ }^{1,2}$, J-F Chastang ${ }^{1,2}$ and D Luce ${ }^{1,2}$ for the EDISC group ${ }^{3}$ \\ 'INSERM, U687, Saint-Maurice F-944I5, France; ${ }^{2}$ IFR69, Villejuif F-94800, France
}

\begin{abstract}
We investigated the time trends in social inequalities in breast cancer mortality with an analysis by age at death and birth cohort using a representative 1\% sample of the French population and four subcohorts (1968-1974, 1975-1981, 1982-1988 and 1990-1996). Causes of death were obtained by direct linkage with the French national death registry. Education was measured at the beginning of each period, and educational disparities in breast cancer mortality were studied among women aged 35-74 at the beginning of each period. In the 1970s, higher breast cancer mortality was found among higher educated women. This positive association progressively weakened and no association remained in the 1990s although it disappeared earlier among younger women. In an analysis by birth cohort, the same pattern was found among women born before 1925, whereas no association between education and mortality was observed among women born after 1925. Educational disparities in breast cancer mortality are currently changing and the previously observed positive gradient has disappeared. An important question is whether these relations are indirect, and due to changes in the prevalence of risk factors associated with education, but which we could not study.
\end{abstract}

British Journal of Cancer (2006) 94, 152- 155. doi:I0.1038/sj.bjc.6602907 www.bjcancer.com

Published online 13 December 2005

(c) 2006 Cancer Research UK

Keywords: breast cancer; mortality; age at death; birth cohort; education; time trends

Unlike most causes of death, breast cancer mortality risks have often been higher among women of high socioeconomic status (Faggiano et al, 1997; Heck et al, 1997; Dano et al, 2003, 2004). Some studies, however, found no such association (Lund and Jacobsen, 1991; Faggiano et al, 1997). Most breast cancer risk factors (reproductive behaviour, diet or physical activity) (Dos Santos Silva and Beral, 1997; Potter, 1997) as well as factors related to cancer survival (screening, treatment) (Auvinen and Karjalainen, 1997; Segnan, 1997) are associated with socioeconomic status and their distribution may have changed over time, producing in turn changes in social inequalities in breast cancer mortality. However, the few studies investigating time trends in social inequalities in breast cancer mortality have shown a decrease in socioeconomic disparities (Wagener and Schatzkin, 1994; Martikainen and Valkonen, 2000).

We have investigated the time trends in social inequalities in breast cancer mortality among women in France during the period $1968-1996$, with analyses by age at death and birth cohort.

*Correspondence: G Menvielle, INSERM U687, HNSM, I4 rue du Val d'Osne, 944I 5 Saint-Maurice Cedex, France;

E-mail: Gwenn.Menvielle@st-maurice.inserm.fr

${ }^{3}$ Members of the EDISC group: Jean-François Chastang, Annette Leclerc, Danièle Luce, Gwenn Menvielle, INSERM U687, Saint-Maurice; Béatrice Geoffroy-Perez, Ellen Imbernon, Institut de Veille Sanitaire DST, SaintMaurice; Christine Couet, Isabelle Robert-Bobée, INSEE, Paris; MarieJosèphe Saurel-Cubizolles, INSERM UI49, Villejuif; Eric Jougla, INSERM CepiDc, Le Vésinet

Received 22 August 2005; revised 14 October 2005; accepted 9 November 2005; published online 13 December 2005

\section{MATERIALS AND METHODS}

In 1968, the French National Statistics Institute (INSEE) created a longitudinal population study (the 'permanent demographic sample' or EDP), which represented roughly $1 \%$ of the French population. The sample includes all persons born on one of four specific calendar dates every year, and is regularly updated to include new subjects with these birthdays (births and immigration). Data are updated at each successive census (1968, 1975, 1982 and 1990). The French National Statistics Institute supervises the keeping of vital records; so the vital status of EDP subjects is systematically monitored (Rouault, 1994). Causes of death were obtained by linkage with the French national death registry (INSERM-CepiDc).

Four subcohorts, each covering a 7-year period, were studied (1968-1974, 1975-1981, 1982-1988, 1990-1996), each beginning in a census year and including all deaths during the following 7 years. Women eligible for each subcohort were those aged 35-74, who responded to the census marking the beginning of the period. Women born outside metropolitan France (around 15\% at each census) were excluded because their vital status was not adequately recorded, especially for foreigners who died abroad. Women for whom data were inconsistent (less than 50 at each census) were also excluded. The cause of death was identified for $95 \%$ of those who died in the 1968-1974 period and $98 \%$ of those who died in later time periods. Analysis focused on breast cancer mortality. The analysis finally included 94734 women in 1968, 99737 women in 1975,100898 women in 1982 and 112066 women in 1990.

Socioeconomic status was measured by educational level, as reported at the census. Educational level was defined as the highest level achieved on the CASMIN classification grid, which is 
designed for international comparisons (Brauns and Steinmann, 1999). We used the following categories: incomplete elementary education (CASMIN level 1a), completed elementary education (CASMIN level $1 \mathrm{~b}$ ), secondary and intermediate general and vocational qualifications (CASMIN level 1c, 2a, 2b), and high school and higher education (CASMIN level $2 c, 3 a$ and $3 b$ ).

Relative risks (RR) were computed with Cox proportional hazards models for each period, using the highest educational level as the reference category. Whereas $\mathrm{RR}$ are easy to interpret, comparisons of RR over time are complicated by possible changes over time in the distribution of educational level in the population, that is, that some groups may grow larger while others become more marginal. The use of the Relative Index of Inequality (RII) as a measure of social inequalities overcomes this problem, providing a continuous measure of social inequalities that simultaneously takes into account the size and relative position of social groups. The RII can be interpreted as the change in mortality when moving from the top to the bottom of the social scale (Pamuk, 1985; Mackenbach and Kunst, 1997; Davey Smith et al, 1998). It differs from the RR, which only gives the ratio between two groups at either end of the socioeconomic range, without taking into account what occurs between these two groups. Relative Indices of Inequality were calculated as follows: a new socioeconomic index was assigned to each individual, equal to the proportion of the population with an educational level higher than that of the subject. This is therefore a continuous index, with a value of 0 for someone at the top of the social scale and 1 for a person at the bottom. To obtain the RII, a Cox regression model was then used to regress mortality on this new socioeconomic index. In all Cox regression models, age was used as the time scale variable.

We first studied social inequalities in breast cancer deaths among all women. Additional analyses were conducted: (1) by age at death, categorised into three categories (less than 50 years old, $50-64,65$ and more); (2) by birth cohort, considering two birth cohorts (born before or in 1925 and born after 1925). The cut point for birth cohort was the midpoint in years of birth for all women included in the analyses (when the four periods were considered).

For each period, we calculated mortality rates among all women adjusted for age by direct standardisation, using the total female person-years for the period 1968-1996 as the standard. Mortality rates were also calculated among women with the highest and the lowest education levels, according to age at death (less than 50 years old, 50-64, 65 and over). Given the small number of deaths in some groups, only crude mortality rates were computed in these analyses.

\section{RESULTS}

The educational level of French women strongly increased during the study period (Table 1): the proportion of women who completed high school or higher education increased from 6.5 to $18.2 \%$, while the proportion of those who did not complete elementary school was halved. The changes were particularly pronounced between the third $(1982-1988)$ and fourth periods
(1990-1996). The proportions of women with only general elementary education decreased slightly throughout the study period, whereas those with a vocational education increased regularly between 1968 and 1990 .

Among all women, changes in social inequalities were observed throughout the study period (Table 2). During the first period (1968-1974), RRs were significantly lower than unity for all educational levels when compared with women with the highest education level. This positive gradient progressively weakened and no association between education and mortality was found during the last period (1990-1996). The RII moved towards unity throughout the study period, being significantly lower than unity (or borderline significant) during the three first periods, and did not significantly differ from unity during the last period (1990-1996). Age-adjusted mortality rates increased throughout the study period.

A similar pattern was observed when analyses were conducted according to age at death (Table 3): a positive association between education and mortality at the beginning of the study period, which progressively disappeared. Among women aged 35-49, this positive association was observed only during the first period (1968-1974); the RIIs were around unity for the following three periods. However, the analyses involved relatively small samples, especially for the first period $(1968-1974)$. This positive association was observed until 1988 among women aged over 65, but among those aged 50-64 only in the first two periods, although it was not significant in the second (1975-1981).

The situation differed according to birth cohort (Table 3). Among women born before 1925, a positive association between education and mortality was found during the first three periods, but no association remained in the last period (1990-1996). Among women born after 1925, no association was seen in any period. Analysis of the first period was not possible because of the small number of deaths.

Crude mortality rates among women with the lowest and the highest education levels (incomplete elementary education and high school and higher education) are presented according to age at death (Figure 1). Over the study period, rates increased among women with a lower education level in all age groups. The pattern is less clear among women with a high education level, but a sharp decrease in mortality rates is noted between the first (1968-1974)

Table I Distribution (\%) according to educational level for each period (French EDP study)

\begin{tabular}{lcccc}
\hline & $\mathbf{1 9 6 8 - 1 9 7 4}$ & $\mathbf{1 9 7 5 - 1 9 8 1}$ & $\mathbf{1 9 8 2 - 1 9 8 8}$ & $\mathbf{1 9 9 0 - 1 9 9 6}$ \\
\hline $\begin{array}{l}\text { High school and } \\
\text { higher education }\end{array}$ & 6.5 & 6.8 & 9.9 & 18.2 \\
$\begin{array}{l}\text { Vocational } \\
\text { education }\end{array}$ & 9.9 & 14.7 & 17.6 & 24.1 \\
$\begin{array}{l}\text { General elementary } \\
\text { education }\end{array}$ & 34.1 & 34.8 & 30.9 & 31.5 \\
$\begin{array}{l}\text { Incomplete } \\
\text { elementary }\end{array}$ & 49.5 & 43.7 & 41.6 & 26.2 \\
education & & & & \\
\hline
\end{tabular}

Table 2 RR, RIl and age-adjusted mortality rates for breast cancer among all women

\begin{tabular}{|c|c|c|c|c|c|c|c|c|}
\hline Period & $\mathbf{N}^{\mathrm{a}}$ & $\begin{array}{r}\text { I } 968-\mid 974 \\
\operatorname{RR}(95 \% \mathrm{CI})\end{array}$ & $\mathbf{N}$ & $\begin{array}{c}|975-| 98 \mid \\
\operatorname{RR}(95 \% \mathrm{CI})\end{array}$ & $\mathbf{N}$ & $\begin{array}{c}|982-| 988 \\
\operatorname{RR}(95 \% \mathrm{CI})\end{array}$ & $\mathbf{N}$ & $\begin{array}{c}1990-1996 \\
\operatorname{RR}(95 \% \mathrm{CI})\end{array}$ \\
\hline Incomplete elementary education & 127 & $0.3(0.2-0.5)$ & 127 & $0.8(0.5-1.3)$ & 159 & $1.0(0.6-1.5)$ & $|5|$ & I.I $(0.8-1.5)$ \\
\hline General elementary education & 84 & $0.4(0.3-0.6)$ & 140 & $1.3(0.8-2.1)$ & 99 & $0.9(0.6-1.4)$ & 152 & $1.0(0.7-1.3)$ \\
\hline Vocational education & 26 & $0.5(0.3-0.8)$ & 38 & $1.0(0.6-1.7)$ & 77 & $1.6(1.0-2.5)$ & 88 & $1.0(0.7-1.3)$ \\
\hline High school and higher education & 34 & I & 18 & I & 26 & I & 62 & I \\
\hline RII $(95 \% \mathrm{Cl})$ & $27 \mid$ & $0.43(0.27-0.68)$ & 323 & $0.61(0.40-0.93)$ & 361 & $0.68(0.46-1.01)$ & 453 & $1.17(0.82-1.68)$ \\
\hline Age-adjusted mortality rate ${ }^{b}$ & & 38 & & 42 & & 46 & & 54 \\
\hline
\end{tabular}

$\mathrm{RR}=$ relative risks; $\mathrm{RII}=$ Relative Index of Inequality; $\mathrm{Cl}=$ confidence interval. ${ }^{\mathrm{a}}$ Number of deaths. ${ }^{\mathrm{b}} \mathrm{Per} 100000$. 
Table 3 Rll according to age at death and birth cohort

\begin{tabular}{|c|c|c|c|c|c|c|c|c|}
\hline Period & $\mathbf{N}^{\mathrm{a}}$ & $\begin{array}{r}\text { I968- I } 974 \\
\text { RII }(95 \% \mathrm{CI})\end{array}$ & $\mathbf{N}$ & $\begin{array}{c}|975-| 98 \mid \\
\text { RII (95\% CI) }\end{array}$ & $\mathbf{N}$ & $\begin{array}{c}\text { I } 982-1988 \\
\text { RII }(95 \% \mathrm{CI})\end{array}$ & $\mathbf{N}$ & $\begin{array}{c}1990-1996 \\
\text { RII (95\% CI) }\end{array}$ \\
\hline \multicolumn{9}{|l|}{ Age at death } \\
\hline $35-49$ & 31 & $0.24(0.06-0.92)$ & 40 & $1.03(0.33-3.17)$ & 46 & $0.92(0.32-2.63)$ & 76 & I.I4 (0.5 I-2.55) \\
\hline $50-64$ & 114 & $0.40(0.20-0.80)$ & 134 & $0.58(0.31-1.10)$ & 154 & $0.82(0.46-1.48)$ & 177 & $1.35(0.78-2.33)$ \\
\hline 65 and more & 126 & $0.54(0.27-1.06)$ & 149 & $0.55(0.30-1.03)$ & 161 & $0.53(0.29-0.95)$ & 200 & $1.12(0.67-1.88)$ \\
\hline \multicolumn{9}{|l|}{ Birth cohort } \\
\hline After 1925 & 12 & $ـ^{b}$ & 65 & $1.02(0.42-2.52)$ & 137 & $0.93(0.50-1.73)$ & 286 & $1.16(0.75-1.81)$ \\
\hline Before 1925 & 259 & $0.44(0.27-0.70)$ & 258 & $0.54(0.34-0.86)$ & 224 & $0.57(0.35-0.93)$ & 167 & $1.26(0.72-2.22)$ \\
\hline
\end{tabular}

$\mathrm{R} I \mathrm{l}=$ Relative Index of Inequality; $\mathrm{Cl}=$ confidence interval. ${ }^{\mathrm{a}}$ Number of deaths. ${ }^{\mathrm{b}}$ Not computed because of the small number of deaths.
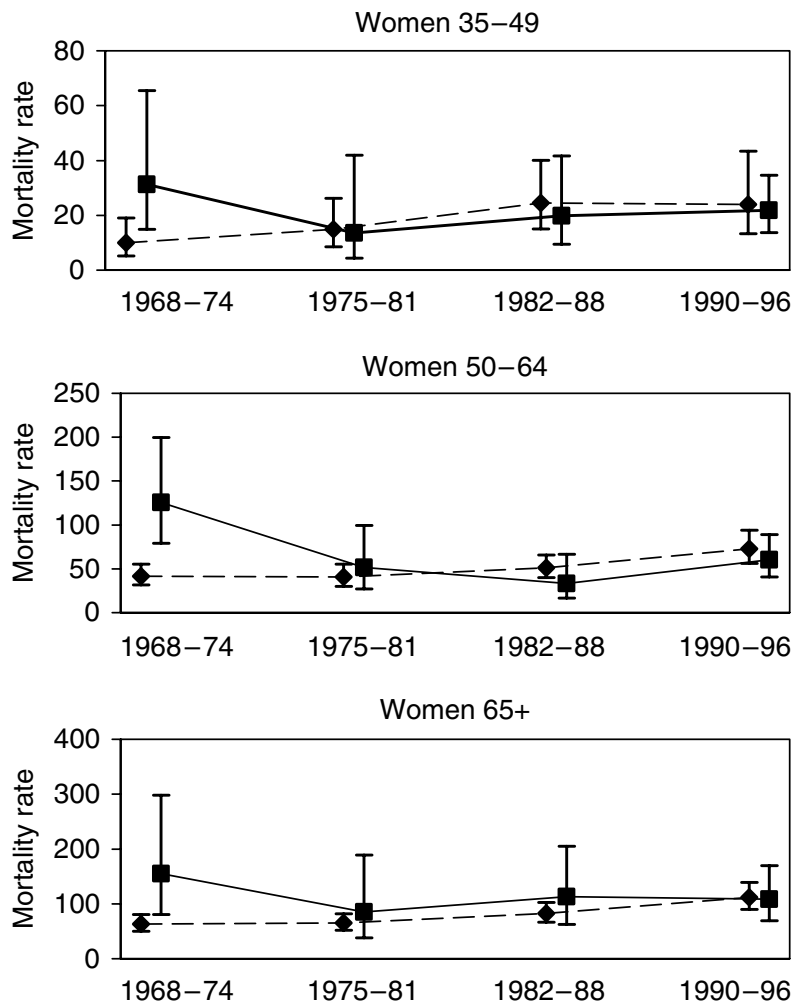

Legend

\section{High education level \\ - $\ldots$ Low education level}

Figure I Trends in breast cancer mortality rates (per 100000) among French women according to education and age at death.

and second periods (1975-1981). Even if confidence intervals overlap, the association reversed throughout the study period. During the first period (1968-1974), the highest rates were observed among highly educated women. Then the rates intersected. This occurred in the 1970s among women aged 3549 , in the early 1980s among women aged 50-64 and in the 1990s among women aged 65 and more. At the end of the study period, rates among women with high and low education levels were close, although they were slightly higher among less educated women.

\section{DISCUSSION}

This study provided a unique opportunity of investigating time trends in educational disparities in breast cancer mortality in
France: the study population is a large, representative sample and individual data on socioeconomic status and specific cause of death were obtained from the same source for all subjects, irrespective of their vital status. Thus, these results are not affected by the numerator/denominator bias of studies in which educational details are derived from different sources for the deceased and the living (Kunst et al, 1998).

Coding for educational level in the census changed slightly in 1990. Some degrees were classified as professional until 1982, being grouped with high school and higher education in 1990. This may lead to a slight underestimation of the educational inequalities level for the last period, but as it concerns only a small proportion of degrees it probably does not much bias the results.

This study throws new light on both social inequalities in breast cancer mortality and their time trends in France. Our analyses by age at death and birth cohort gave consistent results. We found that educational differences in breast cancer decreased between 1968 and 1996 from a positive association in the 1970s until no association remained in the 1990s. This association disappeared earlier among younger women; it was found among women born before 1925, but not among those born after 1925 .

Two studies investigating time trends in social inequalities by broad causes of death found that the positive association between socio-economic status and breast cancer mortality remained stable between 1959-1972 and 1982-1996 (Steenland et al, 2002) or appeared between 1981 and 1991 (McLoone and Boddy, 1994). Two other studies in Finland and the US focused on breast cancer mortality (Wagener and Schatzkin, 1994; Martikainen and Valkonen, 2000). The Finnish study used individual data on education, whereas the American study used an ecological measure; both showed a decrease in social disparities. Our results are in agreement with these findings. During the last few decades, educational level among women strongly increased in all industrialised countries (Martikainen and Valkonen, 2000). The above two studies did not control for this change, but our results show that even after taking this into account (by the use of RII as the measure of social inequalities), social disparities decreased over time.

There are several possible explanations for our findings, but primarily changes in the social distribution of breast cancer risk factors associated with education during the study period. Reproductive factors, diet, alcohol consumption, excess weight, physical activity and genetic factors (family history of breast cancer) are all associated with breast cancer incidence (Hulka and Stark, 1995; Hankinson et al, 2004). Data on these risk factors were not available; so no conclusion can be drawn on their contribution to the observed time trends. Nevertheless, a French study showed that parity decreased with the year of birth for women born between 1917 and 1949, and this was more pronounced among women with lower education levels (Daguet, 2000); this may partly explain the decrease over time of educational disparities for breast cancer. Factors associated with cancer survival may also con- 
tribute. We observed that, within each age group, educational disparities diminished over time. It may be a consequence of better prevention and treatment in recent years, which mostly benefited women with higher education levels, as evidenced by their higher screening rates (use of mammography and breast examination) (Heck et al, 1997; Katz et al, 2000; Gupta et al, 2003; Remontet et al, 2003). This improves the relative position of the educated women in terms of mortality and thereby diminishes the social disparities in breast cancer mortality. In France, systematic screening with mammography began in 1990. Although it has not yet been evaluated in France until now, the introduction of systematic screening is probably too recent to have had an impact on educational disparities during the last period (1990-1996).

There is also some evidence that risk factors for breast cancer may differ for premenopausal and postmenopausal cancers (Hulka and Stark, 1995). Family history of breast cancer is particularly relevant for premenopausal cancers, whereas reproductive and behavioural risk factors are generally more important for postmenopausal cancers. Breast cancer mortality before age 50 may be considered as due to premenopausal cancers. Differences in risk factors according to menopausal status could partly explain why we did not find any association between education and mortality in this age group after 1975, whereas we observed that educational disparities among older women were more pronounced. The literature on educational disparities according to

\section{REFERENCES}

Auvinen A, Karjalainen S (1997) Possible explanations for social class differences in cancer patient survival. IARC Sci Publ 138: $377-397$

Braaten T, Weiderpass E, Kumle M, Adami HO, Lund E (2004) Education and risk of breast cancer in the Norwegian-Swedish women's lifestyle and health cohort study. Int J Cancer 110: 579-583, (doi: 10.1002/ijc.20141)

Brauns H, Steinmann S (1999) Educational reform in France, WestGermany and the United Kingdom: updating the CASMIN educational classification. ZUMA Nachrichten 23: $7-44$

Daguet F (2000) L'évolution de la fécondité des générations nées de 1917 à 1949: analyse par rang de naissance et niveau de diplôme. Population 55: $1021-1034$

Dano H, Andersen O, Ewertz M, Petersen JH, Lynge E (2003) Socioeconomic status and breast cancer in Denmark. Int J Epidemiol 32: 218 224, (doi: 10.1093/ije/dyg049)

Dano H, Hansen KD, Jensen P, Petersen JH, Jacobsen R, Ewertz M, Lynge E (2004) Fertility pattern does not explain social gradient in breast cancer in denmark. Int J Cancer 111: $451-456$, (doi: 10.1002/ijc.20203)

Davey Smith G, Hart C, Hole D, MacKinnon P, Gillis C, Watt G, Blane D, Hawthorne V (1998) Education and occupational social class: which is the more important indicator of mortality risk? J Epidemiol Community Health 52: $153-160$

Dos Santos Silva I, Beral V (1997) Socioeconomic differences in reproductive behaviour. IARC Sci Publ 138: 285-308

Faggiano F, Partanen T, Kogevinas M, Boffetta P (1997) Socioeconomic differences in cancer incidence and mortality. IARC Sci Publ 138: 65-176

Gupta S, Roos LL, Walld R, Traverse D, Dahl M (2003) Delivering equitable care: comparing preventive services in Manitoba. Am J Public Health 93: 2086-2092

Hankinson SE, Colditz GA, Willett WC (2004) Towards an integrated model for breast cancer etiology: the lifelong interplay of genes, lifestyle, and hormones. Breast Cancer Res 6: 213 -218, (doi: 10.1186/bcr921)

Heck KE, Wagener DK, Schatzkin A, Devesa SS, Breen N (1997) Socioeconomic status and breast cancer mortality, 1989 through 1993: an analysis of education data from death certificates. Am J Public Health 87: 1218-1222

Hulka BS, Stark AT (1995) Breast cancer: cause and prevention. Lancet 346: $883-887$

Katz SJ, Zemencuk JK, Hofer TP (2000) Breast cancer screening in the United States and Canada, 1994: socioeconomic gradients persist. Am J Public Health 90: 799-803 menopausal status is particularly scarce, but one study found a slightly steeper gradient among postmenopausal women (Braaten et al, 2004). We found no association between education and breast cancer mortality among women born after 1925. Breast cancer deaths occurring among this birth cohort who were aged $35-50$ in $1975,35-57$ in 1982 and $35-65$ in 1990 were probably not all premenopausal cancers. Thus, we cannot attribute this lack of social inequalities among women born after 1925 to the lack of an association between socioeconomic status and premenopausal breast cancer mortality. The only study of social inequalities by birth cohort found small educational differences in breast cancer mortality among women born after 1935 (Martikainen and Valkonen, 2000).

The findings show that the positive association between education and breast cancer mortality progressively disappeared between 1968 and 1996, and was not observed among women born after 1925. An important question is whether the changes are indirect, and due to changes in the prevalence of breast cancer risk factors associated with education that we could not investigate.

\section{ACKNOWLEDGEMENTS}

This study was partially supported by a grant from a joint project MiRe-CNRS-INSERM. We are grateful to Diane Cyr for her help in English editing.
Kunst AE, Groenhof F, Borgan JK, Costa G, Desplanques G, Faggiano F, Hemstrom O, Martikainen P, Vagero D, Valkonen T, Mackenbach JP (1998) Socio-economic inequalities in mortality. Methodological problems illustrated with three examples from Europe. Rev Epidemiol Sante Publ 46: 467-479

Lund E, Jacobsen BK (1991) Education and breast cancer mortality: experience from a large Norwegian cohort study. Cancer Causes Control 2: $235-238$

Mackenbach JP, Kunst AE (1997) Measuring the magnitude of socioeconomic inequalities in health: an overview of available measures illustrated with two examples from Europe. Soc Sci Med 44: 757-771

Martikainen P, Valkonen T (2000) Diminishing educational differences in breast cancer mortality among Finnish women: a register-based 25-year follow-up. Am J Public Health 90: 277-280

McLoone P, Boddy FA (1994) Deprivation and mortality in Scotland, 1981 and 1991. BMJ 309: 1465-1470

Pamuk E (1985) Social class inequality in mortality from 1921 to 1972 in England and Wales. Population Stud 39: 17-31

Potter J (1997) Diet and cancer: possible explanations for the higher risk of cancer in the poor. IARC Sci Publ 138: $265-283$

Remontet L, Esteve J, Bouvier AM, Grosclaude P, Launoy G, Menegoz F, Exbrayat C, Tretare B, Carli PM, Guizard AV, Troussard X, Bercelli P, Colonna M, Halna JM, Hedelin G, Mace-Lesec'h J, Peng J, Buemi A, Velten M, Jougla E, Arveux P, Le Bodic L, Michel E, Sauvage M, Schvartz C, Faivre J (2003) Cancer incidence and mortality in France over the period 1978-2000. Rev Epidemiol Sante Publique 51: $3-30$

Rouault D (1994) The Echantillon Démograhique Permanent: a French equivalent to the Longitudinal Study. Update - News from the LS User Group January 1994, pp 5-13

Segnan N (1997) Socioeconomic status and cancer screening. IARC Sci Publ 138: $369-376$

Steenland K, Henley J, Thun M (2002) All-cause and cause-specific death rates by educational status for two million people in two American Cancer Society cohorts, 1959-1996. Am J Epidemiol 156: 11-21, (doi: 10.1093/aje/kwf001)

Wagener DK, Schatzkin A (1994) Temporal trends in the socioeconomic gradient for breast cancer mortality among US women. Am J Public Health 84: $1003-1006$ 